\title{
Characterization of Glass Fibre Reinforced Polymer Composite Prepared by Hand Layup Method
}

\author{
Abdullah Al Mahmood, Abdul Mobin, Rezwon Morshed, Tasmia Zaman \\ Department of Glass \& Ceramic Engineering, Rajshahi University of Engineering \& Technology (RUET), Rajshahi, Bangladesh \\ Email address: \\ abdullah2038@gmail.com (A. A. Mahmood)

\section{To cite this article:} \\ Abdullah Al Mahmood, Abdul Mobin, Rezwon Morshed, Tasmia Zaman. Characterization of Glass Fibre Reinforced Polymer Composite \\ Prepared by Hand Layup Method. American Journal of Bioscience and Bioengineering. Vol. 5, No. 1, 2017, pp. 8-11. \\ doi: $10.11648 /$ j.bio.20170501.12
}

Received: December 18, 2016; Accepted: January 10, 2017; Published: February 4, 2017

\begin{abstract}
In this work, glass fiber reinforced epoxy composites were fabricated. Epoxy resin was used as polymer matrix material and glass fiber was used as reinforcing material. The main focus of this work was to fabricate this composite material by the cheapest and easiest way. For this, hand layup method was used to fabricate glass fiber reinforced epoxy resin composites and $\mathrm{TiO}_{2}$ material was used as filler material. Six types of compositions were made with and without filler material keeping the glass fiber constant and changing the epoxy resin with respect to filler material addition. Mechanical properties such as tensile, impact, hardness, compression and flexural properties were investigated. Additionally, microscopic analysis was done. The experimental investigations show that without filler material the composites exhibit overall lower value in mechanical properties than with addition of filler material in the composites. The results also show that addition of filler material increases the mechanical properties but highest values were obtained for different filler material addition. From the obtained results, it was observed that composites filled by $15 \mathrm{wt} \%$ of $\mathrm{TiO}_{2}$ particulate exhibited maximum tensile strength, $20 \mathrm{wt} \%$ of $\mathrm{TiO}_{2}$ particulate exhibited maximum impact strength, $25 \mathrm{wt} \%$ of $\mathrm{TiO}_{2}$ particulate exhibited maximum hardness value, $25 \mathrm{wt} \%$ of $\mathrm{TiO}_{2}$ particulate exhibited maximum compressive strength, $20 \mathrm{wt} \%$ of $\mathrm{TiO}_{2}$ particulate exhibited maximum flexural strength.
\end{abstract}

Keywords: Glass Fiber, Polymer Composites, Epoxy Resin, Filler

\section{Introduction}

Fibre reinforced polymer (FRP) are composites used in almost every type of advanced engineering structure, with their usage ranging from aircraft, helicopters and spacecraft through to boats, ships and offshore platforms and to automobiles, sports goods, chemical processing equipment and civil infrastructure such as bridges and buildings. A key factor driving the increased applications of composites over the recent years is the development of new advanced forms of FRP materials. This includes developments in high performance resin systems and new styles of reinforcement, such as glass fiber, carbon fiber, nanoparticles etc. [1].

Composite materials are produced by combining two dissimilar materials into a new material that may be better suited for a particular application than either of the original materials alone. The most common example of a composite material is the glass fiber reinforced plastic commonly used in household goods and in many industrial applications. Composites are made up of individual materials referred to as constituent materials. There are two main categories of constituent materials: matrix and reinforcement. At least one portion of each type is required. The matrix material surrounds and supports the reinforcement materials by maintaining their relative positions. The reinforcements impart their special mechanical and physical properties to enhance the matrix properties [2]. Epoxy resins are widely used as matrix in many fiber reinforced composites; they are a class of thermoset materials of particular interest to structural engineers owing to the fact that they provide a unique balance of chemical and mechanical properties combined with wide processing versatility. Within reinforcing materials, glass fibers are the most frequently used in structural constructions because of their specific strength properties [3].

However, these composites have some disadvantages related to the matrix dominated properties which often limit their wide applications. In the industry, the addition of filler 
materials to a polymer is a common practice. This improves not only stiffness, toughness, hardness, heat distortion temperature, and mold shrinkage, but also reduces the processing cost significantly. In fact, more than $50 \%$ of all produced polymers are in no way or another filled with inorganic fillers to achieve the desired properties [4]. Mechanical properties of fiber- reinforced composites are depending on the properties of the constituent materials (type, quantity, fiber distribution and orientation, void content). Beside those proper- ties, the nature of the interfacial bonds and the mechanisms of load transfer at the interphase also play an important role [5]. The present study focuses on fabrication and investigation of GFRP laminated composites without and with filler material $\mathrm{TiO}_{2}$.

\section{Experimental Procedure}

The following materials were used for the fabrication of GFRP-epoxy composites:

- Epoxy resin

- Epoxy hardener ( curing agent of epoxy resin)

- Glass fiber

Table 1. Compositions of fabricated composites.

\begin{tabular}{llll}
\hline Composites group & $\begin{array}{l}\text { Glass Fiber } \\
(\mathbf{w t} \%)\end{array}$ & $\begin{array}{l}\text { Epoxy Resin } \\
\text { (wt\%) }\end{array}$ & $\mathbf{T i O}_{\mathbf{2}} \mathbf{( \mathbf { w t } \% )}$ \\
\hline $\mathrm{C} 1$ & 30 & 70 & 0 \\
$\mathrm{C} 2$ & 30 & 60 & 10 \\
$\mathrm{C} 3$ & 30 & 55 & 15 \\
$\mathrm{C} 4$ & 30 & 50 & 20 \\
$\mathrm{C} 5$ & 30 & 45 & 25 \\
$\mathrm{C} 6$ & 30 & 40 & 30 \\
\hline
\end{tabular}

Hand layup method was used for preparing the laminated composites sample. At first plywood board was taken around $2 \mathrm{ft}$ by $1 \mathrm{ft}$ for making desired pattern. Plastic tape placed on plywood board. In this work, plywood board acted as open mold instead of metal mold or any other kind of mold. Because plywood is cheap, very light weight, easily can be handled. As we made flat type sample so plywood with flat design was used and it was suitable for our working. Plastic tape acted as releasing agent.

Glass fiber was cut previously according to desired dimension. Glass fiber was cut by scissor. Then glass fibers were taken for weighing. Glass fibers were weighed by electric weight balance. From glass fibers weight, epoxy resin, hardener and filler material were weighed based on different compositions. Six types of compositions were made for each mechanical property testing. For tensile testing, according to required dimension, 184gm glass fiber taken as 30\%. Epoxy resin was taken 429.33gm for C1 composite. Epoxy hardener was mixed with epoxy resin in 10:1 (resin: hardener) ratio. So, $42.933 \mathrm{gm}$. hardener was taken for $\mathrm{C} 1$ composite. For C2 composite, $368 \mathrm{gm}$ epoxy resin was taken. Hardener was taken $36.8 \mathrm{gm}$. Filler material $\mathrm{TiO}_{2}$ was $61.33 \mathrm{gm}$ for $\mathrm{C} 1$. Hence, for $\mathrm{C} 3, \mathrm{C} 4, \mathrm{C} 5$ and $\mathrm{C} 6$ weight of resin, hardener and filler material were taken. For other testing's like hardness testing, impact testing, compression testing, flexural strength testing glass fibers were weighed in same way that was described in above and from glass fibers weight, according to composition resin, hardener and $\mathrm{TiO}_{2}$ were weighed.

After weighing, a layer of glass fibers was placed on the surface of the pattern. Then mixture of epoxy resin and hardener as well as with or without $\mathrm{TiO}_{2}$, depending on compositions, poured onto the surface of the glass fibers mat. Resin mixture was uniformly sprayed with the help of 2.5 inches brush. Second layer of mat was then placed on the resin mixture surface and compressed by brush with a mild pressure on the mat-resin mixture layer to remove air as well as excess resin present. The process was repeated for each layer of resin plus hardener mixture or resin plus hardener plus filler material mixture and mat, till the required layers were stacked. After achieving desired thickness, the laminated composites were kept for 48 hours at room temperature for curing. After curing, specimens were withdrawn from the pattern. Then samples were cut by grinding machine according to required testing dimensions.

Tensile, Compressive \& Flexural tests were carried out using universal testing machine. The testing range of that UTM machine is 20 to $200 \mathrm{KN}$. Impact test was carried out using Avery type 6703, serial E65422/2 charpy impact tester. Rockwell hardness test was carried out using Gemco Telex 59388 Rockwell hardness tester.

For tensile testing, test specimens were prepared according to ASTM D3039 $(317 \times 25 \times 4) \mathrm{mm}$. For impact testing, test specimens were prepared according to ASTM E23 $(55 \times 10 \times 10)$ $\mathrm{mm}$. For hardness testing, test specimens were prepared according to ASTM D785 $(30 \times 30 \times 6.4) \mathrm{mm}$. For compressive testing, test specimens were prepared according to ASTM D3140 $(140 \times 12.7 \times 3) \mathrm{mm}$. For flexural strength testing, test specimens were prepared according to ASTM D790 $(80 \times 10 \times 4)$ $\mathrm{mm}$.

\section{Results and Discussion}

Fibers are the main load carrying agents in composites and as the number of load carrying elements increases in a material, its strength increases. Also the tensile strength of the composites increases with increasing the fiber volume fraction [6]. The decrease in strength with increasing the particles volume fraction may be due to non-wetting behavior of the filler particles with the matrix and may be due to the non-uniform distribution of the particles. The efficiency of load transfer between the matrix and reinforcements depends directly on the bonding which in turn depends on wetting of surfaces. The non-uniform distribution of particles may reduce wetting and bonding, and as a result of excessive particles that are not well dispersed in the polymer, stress concentrations and defects will be created in the matrix, and thus decreases the tensile strength [7]. In general, the clustering or entanglement of particles and/or fibers in some areas and the irregularities may create resin poor areas and so weaken the forces of adhesions well as creating many of defects within the composites and other defects formed within the fiber layer itself and that this will lead to the generation of 
many areas to focus the stresses which accelerate the process of failure of the sample and making the material behave as a brittle [8]. In figure 1 the effect of $\mathrm{TiO}_{2}$ on the tensile strength of the composite has been illustrated.

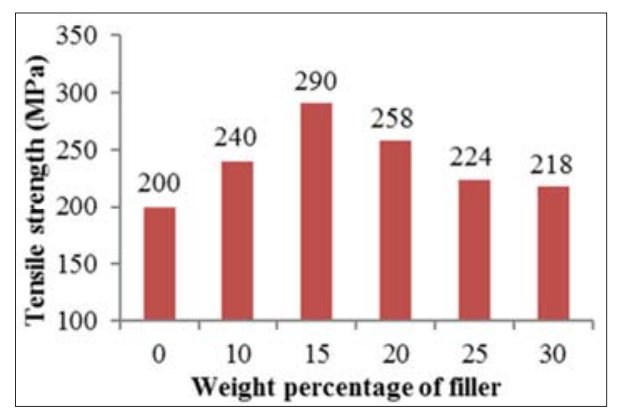

Figure 1. Comparison of tensile strength for GFRP composites.

The addition of particles during hybrid composite preparation can lead to form a high viscose mixture that may lead to decrease resin wettability which in turn weakening the linkage between matrix and reinforcement and that is an additional reason for the lower results of particle composites [9]. Particle fillers (especially ceramics) may act as points for a localized stress concentration, from which the failure will begin, also it may help in the reduction of elasticity of material and reducing the deformability of matrix and in turn the ductility, so that the composite tends to form a weak structure also, the bad distribution of fillers reduces the ability of matrix to absorb energy and thereby reducing the toughness, so impact energy decreases [10].

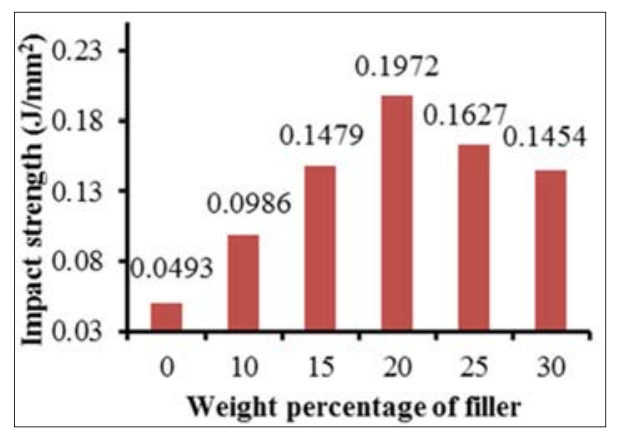

Figure 2. Comparison of impact strength for GFRP composites.

The increase in fracture toughness may be related to particulate fillers that may act as obstacles that will retard the crack growth in the prepared composite system and this will cause the crack deflection in shape and direction i.e. blunting of crack tip will be expected, then toughness be increased, while decrease in the fracture toughness may be related to the bond weakness between the matrix and the particulate filler [11].

Result in figure 3 has revealed that the hardness of glass fiber reinforced composite without the filler material is $56 \mathrm{HR}$ compared to the maximum value of $71 \mathrm{HR}$ for the addition of filler material. The reason for the increased values of hardness is due to the increased cross-linking and stacking which reduces the movement of polymer molecules and making it to become more resistant to the penetration of indenter [12].

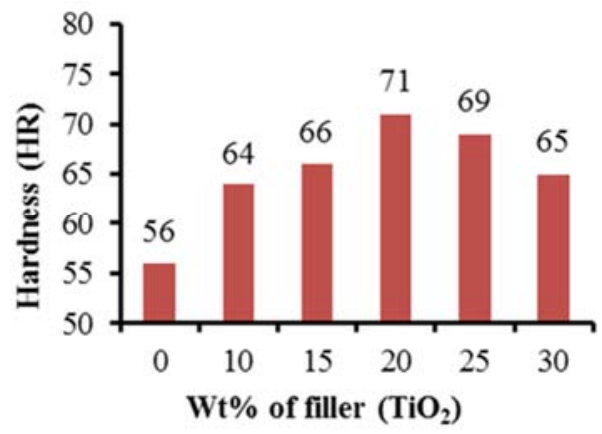

Figure 3. Comparison of hardness value for GFRP composites.

Figure 4 shows that the compressive strength was found highest for the filler content $25 \%$. Having filler content $25 \%$, the glass fiber reinforced polymer composite gives the highest compressive strength $285 \mathrm{~N} / \mathrm{mm}^{2}$.

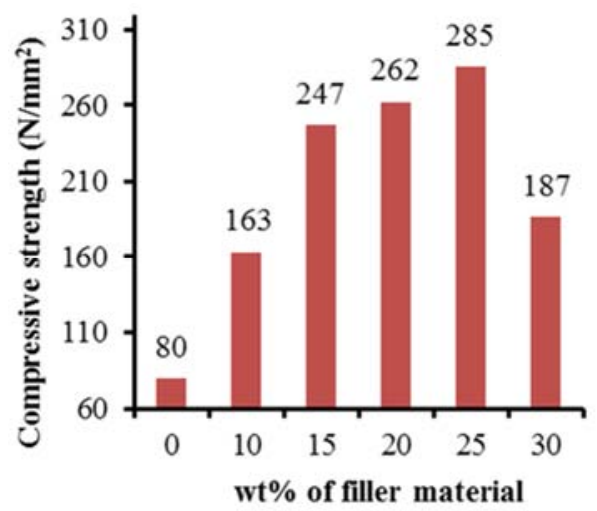

Figure 4. Comparison of compressive strength for GFRP composites.

In general, the clustering or entanglement of particles and/or fibers in some areas and the irregularities may create resin poor areas and so weaken the forces of adhesions and this will lead to the generation of many areas to focus the stresses which accelerate the process of failure of the sample and making the material behave as a brittle.

Figure 5 represents the Flexural strength and modulus were found to increases significantly as the fibre content increased up to 20 wt. \%. Lower flexural strength and modulus were observed for the composites with lower filler content.

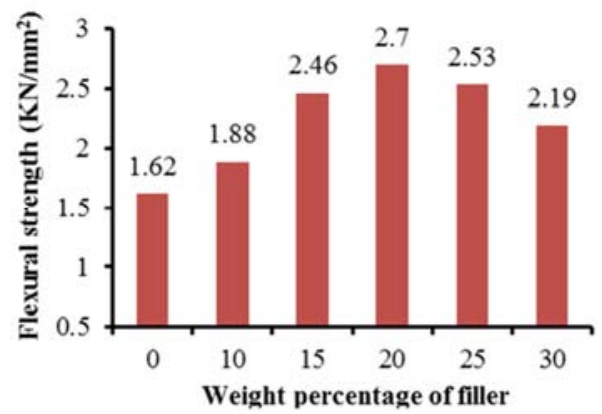

Figure 5. Comparison of flexural strength for GFRP composites.

Decreasing of flexural strength begins, where increasing the 
addition of filler lead to increasing the constrained between polymer chains, decreasing the length of chains over certain critical length. This lead to decreasing flexural strength which is depend on chain length, but flexural strength still higher for neat epoxy resin because of van der Waals bond which is weak bond but with huge numbers [13].

\section{Conclusions}

Glass fiber reinforced epoxy resin composites were fabricated using hand lay up method. Mechanical properties were investigated for different compositions of GFRE composites. Tensile, Impact, Hardness, Compression, Flexural values were higher for $\mathrm{TiO}_{2}$ filled composites than unfilled composites. Microscopic analysis was also done for GFRP composite. Investigations show that the composite having $15 \mathrm{wt} \% \mathrm{TiO}_{2}$ having maximum tensile strength of 290 $\mathrm{MPa}, 20 \mathrm{wt} \% \mathrm{TiO}_{2}$ having maximum impact strength of $0.1972 \mathrm{~J} / \mathrm{mm}^{2}, 20 \mathrm{wt} \% \mathrm{TiO}_{2}$ having maximum Rockwell hardness number of $71 \mathrm{HR}, 25 \mathrm{wt} \% \mathrm{TiO}_{2}$ having maximum compression strength of $285 \mathrm{~N} / \mathrm{mm}^{2}, 20 \mathrm{wt} \% \mathrm{TiO}_{2}$ having maximum flexural strength of $2.70 \mathrm{KN} / \mathrm{mm}^{2}$. So it is cleared from experimental results that mechanical properties increases with addition of filler material. It is also cleared from investigations that filler material content having $20 \mathrm{wt} \%$ exhibited better mechanical properties than other filler contents or without filler content composites. The results indicate that with increasing filler material mechanical strength increases but at certain composition composite shows highest strength then fall down. The surface of filler and without filler material and mixing conditions of the composites were studied with metallurgical microscope images. It is occurred due to non uniform mixing or void content or excessive use of filler material lead to high form of viscous mixture that lead to weak bonding between resin, filler and reinforcing material.

\section{References}

[1] Tong L., Mouritz A. P., Bannister M. 3D Fibre Reinforced Polymer Composites. Elsevier 2002.
[2] O. P KHANNA "A Text Book of MATERIAL SCIENCE AND METALLURGY”. $1^{\text {st }}$ edition (1993), 23-1.

[3] Patil Deogonda, Vijaykumar N Chalwa. "Mechanical Property of Glass Fiber Reinforcement Epoxy Composites". Vol. 1, Issue 4 (2013).

[4] R. N. Rothon, "Mineral Fillers in Thermoplastics: Filler Manufacture and Characterization," Advances in Polymer Science, Vol. 139, 1999, pp. 67-107.

[5] Cs. Varga, N. Miskolczi, L. Bartha and G. Lipoczi, "Improving the Mechanical Properties of Glass-Fibre-Reinforced Polyester Composites by Modification of Fibre Surface," Materials and Design, Vol. 31, 2010, pp. 185-193.

[6] Khanam P. N., "Journal of polymer and the environment", "Sisal / carbon fiber reinforced hybrid Composites: tensile, flexural \& chemical resistance properties", Vo. 18, N.4, 2010, 727.

[7] Hanna W. A., Gharib F. E. \& Marhoon I. I., "Journal of Minerals \& Materials Characterization \& Engineering", "Characterization of ceramic filled polymer matrix composite used for biomedical application", Vo.10, N.12, 2011, 1167-1178.

[8] MYERS D. S.," University of Oklahoma Graduate College", "Fiber-Reinforced Concrete and Bridge Deck cracking", 2006, 48.

[9] Saleh E. S., Shabib K. R. \& Hamad Q. A., "Eng. \& Tech. Journal", "Studying mechanical properties for polymer matrix composite material reinforced by fibers and particles", Vo.28, N.4, (2010), PP.86. (In Arabic.

[10] SAM A. R. M., "Faculty of civil engineering, University Technology, Malaysia", "Application of polymer in concrete construction", 2007, 19.

[11] Hayder A. S., "University of Technology", "Ceramic Filled Polymer Matrix Composite used for Biomedical Application", 2010, 59.

[12] Ahmed J. K., Haleem A. H. \& Omran A. R., "Effect of Glass fiber surface treatment on the flexural strength and interfacial properties of glass fiber-polyester composite".

[13] Anand Kumar Gupta, V. R. Balakrishnan and S. K. Tiwary, "International Journal Polymer Technology, Vol. 1, No.2-3, 2009, PP 181-188. 